Chapman University

Chapman University Digital Commons

Psychology Faculty Articles and Research

Psychology

2011

\title{
Unconscious Vigilance: Worldview Defense Without Adaptations for Terror, Coalition or Uncertainty Management
}

Colin Holbrook

University of California - Los Angeles

Paulo Sousa

Queen's University Belfast

Jennifer Hahn-Holbrook

Chapman University, hahnholb@chapman.edu

Follow this and additional works at: http://digitalcommons.chapman.edu/psychology_articles

Part of the Social Psychology Commons

\section{Recommended Citation}

Holbrook, C., Sousa, P., \& Hahn-Holbrook, J. (2011). Unconscious vigilance: Worldview defense without adaptations for terror, coalition or uncertainty management. Journal of Personality and Social Psychology, 101, 451-466. doi: 10.1037/a0024033

This Article is brought to you for free and open access by the Psychology at Chapman University Digital Commons. It has been accepted for inclusion in Psychology Faculty Articles and Research by an authorized administrator of Chapman University Digital Commons. For more information, please contact laughtin@chapman.edu. 


\section{Unconscious Vigilance: Worldview Defense Without Adaptations for Terror, Coalition or Uncertainty Management}

\section{Comments}

This is a pre-copy-editing, author-produced PDF of an article accepted for publication in Journal of Personality and Social Psychology, volume 101, 2011 following peer review. This article may not exactly replicate the final version published in the APA journal. It is not the copy of record. The definitive publisher-authenticated version is available online at DOI:10.1037/a0024033.

\section{Copyright}

American Psychological Association 


\title{
Unconscious Vigilance: Worldview Defense Without Adaptations for Terror, Coalition, or Uncertainty Management
}

\author{
Colin Holbrook, \\ Center for Behavior, Evolution, and Culture, Department of Anthropology, University of California, \\ Los Angeles
}

Paulo Sousa, and

Institute of Cognition and Culture, Queen's University Belfast, Belfast, Northern Ireland

Jennifer Hahn-Holbrook

Department of Psychology, University of California, Los Angeles

\begin{abstract}
Individuals subtly reminded of death, coalitional challenges, or feelings of uncertainty display exaggerated preferences for affirmations and against criticisms of their cultural in-groups. Terror management, coalitional psychology, and uncertainty management theories postulate this "worldview defense" effect as the output of mechanisms evolved either to allay the fear of death, foster social support, or reduce anxiety by increasing adherence to cultural values. In 4 studies, we report evidence for an alternative perspective. We argue that worldview defense owes to unconscious vigilance, a state of accentuated reactivity to affective targets (which need not relate to cultural worldviews) that follows detection of subtle alarm cues (which need not pertain to death, coalitional challenges, or uncertainty). In Studies 1 and 2, death-primed participants produced exaggerated ratings of worldview-neutral affective targets. In Studies 3 and 4, subliminal threat manipulations unrelated to death, coalitional challenges, or uncertainty evoked worldview defense. These results are discussed as they inform evolutionary interpretations of worldview defense and future investigations of the influence of unconscious alarm on judgment.
\end{abstract}

\section{Keywords}

worldview defense; subliminal threat; terror management theory; coalitional psychology; uncertainty management theory

Conscious thought is effortful and slow. In a perilous, ever-changing world, we cannot rely on reflective processes to mobilize responsiveness to subtle indications of threat (Liddell et al., 2005). We propose that this need is served by unconscious vigilance: increased sensitivity to affective stimuli initiated by alarming cues processed below the threshold of conscious awareness.

Theoretically, unconscious vigilance heightens reactions to stimuli affectively indexed as resources or hazards by intensifying the acuity with which they are perceived.1 For instance,

\footnotetext{
(C) 2011 American Psychological Association

Correspondence concerning this article should be addressed to Colin Holbrook, Center for Behavior, Evolution, and Culture, Department of Anthropology, 341 Haines Hall Box 951553, University of California, Los Angeles, Los Angeles, CA 90095-1553. cholbrook01@ucla.edu.

${ }^{1}$ For purposes of exposition, we use the term affect in a comprehensive sense including emotions, moods, and undifferentiated valenced states (for a review of affect typologies, see Prinz, 2004).
} 
a hiker may register positively regarded environmental targets, such as a secure nearby cabin, with enhanced salience after peripherally glimpsing a grizzly through dense trees. Alternately, the same unconsciously vigilant hiker might react with greater and more immediate aversion should the grizzly step into the open. As these examples illustrate, unconscious vigilance can potentiate responsiveness to an eliciting stimulus (e.g., the grizzly) or to other integrally related targets (e.g., the cabin refuge). Importantly, unconscious vigilance should also accentuate sensitivity to affective stimuli that are incidental to the eliciting trigger. For example, our unconsciously vigilant hiker might encounter a sun-dappled stream with greater pleasure or a discarded beer can with greater annoyance.

A wide cognitive neuroscience literature supports the existence of unconscious vigilance (for a review, see L. M. Williams et al., 2006). The amygdala, for example, is conceptualized as a kind of searchlight that directs perception and attention to either threat or reward stimuli of motivational significance (Barrett, 2006; Berridge, 1999; Holland \& Gallagher, 1999; Wager et al., 2008). Upon exposure to subtle threats (e.g., subliminal fearful faces), the amygdala is theorized to excite brain stem mechanisms that innervate broad regions of the brain, "accessing the cortex to further the evaluation of significant stimuli and to facilitate automatic orienting and the eventual experience of emotion within awareness" (Liddell et al., 2005, p. 241). The amygdala and the anterior cingulate have both been implicated in "alarm" reactions to unconsciously processed affective stimuli, particularly cues of threat (Eisenberger \& Lieberman, 2004; LeDoux, 1996; Lieberman, 2007; Whalen et al., 1998), including counterfactual thoughts of prospective threat (Nitschke et al., 2009). In contrast, conscious detection of threat activates higher cortical areas, enabling topdown control of behavioral responses (L. M. Williams et al., 2006) and inhibiting alarm signals in the amygdala (Hariri, Bookheimer, \& Mazziotta, 2000; Lieberman et al., 2007) and the anterior cingulate (Lieberman et al., 2004). Thus, to influence evaluation, subtle cues must be alarming enough to arouse unconscious vigilance but not so alarming as to recruit conscious awareness and emotion regulation.

Our phylogenetic cousins appear to share the capacity to heighten reactivity to affective stimuli upon detecting subtle alarm cues. For example, Herry et al. (2007) compared the influence of random tone intervals (i.e., subtle cues of environmental unpredictability) on the reactions of mice and humans to affective stimuli. In both species, the random interval manipulation induced hyper-responsiveness in the amygdala coupled with behavior indicative of accentuated reactivity to affective targets: Mice sought enclosed spaces more avidly, and humans were more sensitive to angry faces in a dot-probe task despite the absence of self-reported changes in their conscious emotional awareness. In a conceptually similar study manipulating subtle visual cues of alarm, van den Bos et al. (2008) found that exposure to either background exclamation marks in a laboratory setting or blinking lights across the street in field studies increased self-reported anger toward injustice (e.g., vignettes involving unfair employment practices). Consistent with the unconscious vigilance perspective, and just as Herry et al. found with their manipulation of random tone intervals, the "alarmed" participants in the injustice studies did not report conscious awareness of emotional upset despite showing significantly intensified reactivity to affective targets. When alarm cues register unconsciously, consciously perceived affective stimuli appear to evoke exaggerated reactions but not awareness of having shifted into a state of vigilance.

Unconscious vigilance appears likely to operate in the aftermath of initially conscious alarm reactions as well as when initiated by subtle alarm cues present in the immediate surroundings. Several minutes after narrowly avoiding a fender-bender, for example, an unconsciously vigilant driver might respond to a catchy song with greater relish, or to a disagreeable talk radio rant with greater repellence. In this manner, unconscious vigilance 
may bias evaluations of incidental targets, including complex cultural stimuli, by intensifying the pleasantness or aversiveness with which they are later perceived. Indeed, numerous studies have found that initially conscious reminders of threats that do not subsequently arouse conscious distress engender a form of evaluation bias termed worldview defense - the polarization of ratings for pleasant and against aversive cultural attitudes (Greenberg, Solomon, \& Pyszczynski, 1997; Kirkpatrick \& Navarrete, 2006; McGregor, 2006). In what follows, we argue that researchers investigating worldview defense, although motivated by unrelated theoretical frameworks, have generated evidence that unconscious vigilance can bias incidental evaluations of pleasant or aversive cultural stimuli.

Worldview defense has been demonstrated to follow subtle or entirely subliminal threats in hundreds of experiments conducted over roughly the past two decades, and has become the subject of considerable controversy (e.g., Kirkpatrick \& Navarrete, 2006; Landau, Solomon, Pyszczynski, \& Greenberg, 2007; McGregor, 2006). Terror management theory, coalitional psychology, and uncertainty management theory2 advance distinct proposals of the evolutionary origins of worldview defense (Greenberg et al., 1997; McGregor, 2006; Navarrete, 2005). Our primary aim in this article is to test whether the effects reported in the worldview defense literature are more parsimoniously explained by unconscious vigilance or a cognitive architecture specially related to the endorsement of group values, as each of the previous theories has maintained. A corollary goal of the experiments reported here is to test whether unconscious vigilance biases evaluations of incidental valenced targets, from simple aesthetic stimuli to ideological cultural essays, in the theorized manner. Before proceeding to our studies, we first summarize current debates between the terror, coalition, and uncertainty management perspectives on worldview defense, then we critique prior attempts to rule out alternative explanations such as unconscious vigilance.

\section{Functional Accounts of Worldview Defense}

We begin with a rough overview of the prior accounts of worldview defense before examining each in greater detail. Terror management theory attributes worldview defense to a psychological system designed to suppress the fear of death via identification with cultural worldviews, which are thought to confer a sort of symbolic immortality (Greenberg et al., 1997; Landau et al., 2007). The mortality-salience hypothesis asserts that once thoughts of death become salient, a specialized "death anxiety buffer" weakens such that worldviews must be endorsed more emphatically to keep the fear of death at bay (Greenberg et al., 1990). Alternatively, the coalitional psychology interpretation holds that death cues trigger worldview defense because typical causes of death in the ancestral past were amenable to social support (Navarrete, Kurzban, Fessler, \& Kirkpatrick, 2004). On this account, worldview defense arises from an adaptation for broadcasting in-group allegiance to solicit help and to foster social relations in times of need (Kirkpatrick \& Navarrete, 2006; Navarrete \& Fessler, 2005). Finally, uncertainty management theory argues that mortalitysalience spurs worldview defense because death numbers among a range of topics about which people are profoundly unsure or regard as conflicting with their personal goals. From this perspective, cues of personal uncertainty or other poignant threats motivate exaggeratedly definite, "zealous" cultural stances that assuage the anxiety that would otherwise follow (McGregor, 2006; McGregor \& Marigold, 2003; McGregor, Zanna, Holmes, \& Spencer, 2001).

\footnotetext{
${ }^{2}$ This theory should not be confused with Gudykunst's (1993) anxiety/uncertainty management theory of interpersonal communication.
} 
The terror, coalition, and uncertainty management accounts contest the evolved origins and nature of the mechanisms underlying worldview defense. 3 For example, terror management theory ascribes worldview defense to a cognitive adaptation engineered by natural selection to resolve the potential for debilitating fear posed by early humans' "burgeoning awareness of the inevitability of death" (Landau et al., 2007, p. 490). As the principal architects of terror management theory made plain, "unique support for [terror management theory] is predicated on the assumption that mortality salience effects are engendered specifically by concerns about one's own mortality rather than in response to any anxiety-provoking or selfthreatening event" (Greenberg et al., 1997, p. 98). Consequently, the repeated findings that coalitional or uncertainty primes engender worldview defense pose a serious challenge to terror management theory. Recent defenses of terror management theory attempt to counter this mounting evidence, explaining that

many events not directly tied to death remind people of death anyway ... For example, [uncertain] thoughts of what a place where significant events from one's life occurred will be like 35 years from today are likely to highlight the transient nature of life (McGregor et al., 2001); thoughts of uncertainty may remind one of the flimsy nature of one's views about the world (van den Bos, 2001); and thoughts of being robbed [manipulated in coalitional psychology studies] may bring to mind the very real possibility that the robbery will entail the threat of potentially lethal violence. (Landau et al., 2007, p. 504)

However, the argument that uncertainty or coalition primes cause worldview defense because they indirectly induce mortality-salience overlooks the manipulation checks that uncertainty management and coalitional psychology researchers have conducted to confirm that death thoughts are not inadvertently aroused by their manipulations (Navarrete et al., 2004, Study 2; van den Bos, 2001; van den Bos, Poortvliet, Maas, Miedema, \& van den Ham, 2005).

From the coalitional psychology perspective, "the mortality-salience phenomena documented by terror management researchers are best explained as the social-cognitive output of a system of adaptive mechanisms that facilitate the formation of social networks, interpersonal attachments, and coalitions" (Navarrete \& Fessler, 2005, p. 307). Thoughts of death, therefore, elicit

increased endorsement of the normative beliefs of the ingroup primarily because the likely common causes of death in ancestral environments (dire illness, disease, severe bodily harm, and starvation) were conditions in which successfully acquiring increased social support (and perhaps, avoiding outgroup members) would have had significant fitness consequences. (Kirkpatrick \& Navarrete, 2006, p. 294)

Given the fitness benefits of affiliating with others more intensely following cues of "situations that pose adaptive problems for the individual that could conceivably be effectively addressed using the support of allies" (Kirkpatrick \& Navarrete, 2006, p. 295), the coalitional relations approach argues that selection should have favored the design of psychological mechanisms that heighten group normativity upon detection of coalitionally relevant threats. Consistent with this proposal, subtle reminders of robbery and social isolation have led to worldview defense in several studies (Navarrete, 2005; Navarrete et al.,

\footnotetext{
${ }^{3}$ Our discussion of the uncertainty management account of the phylogenetic origins of worldview defense focuses on the proposals of McGregor and colleagues (e.g., McGregor, 2006). In a recent article, however, van den Bos et al. (2008) also advanced the possibility that some uncertainty-salience effects on evaluation owe to an ancient background threat-detection mechanism. The threat-detection mechanism sketched by the van den Bos group is left somewhat open and should not necessarily be equated with the goal-pursuit system hypothesized by McGregor and his fellow researchers.
} 
2004). Coalitional psychology theory synthesizes these findings with the numerous reports that reminders of uncertainty also produce worldview defense on the grounds that because "others are often able to provide direction and aid in uncertain situations ... these results are consistent with our thesis that increases in normative orientation are ultimately aimed at recruiting assistance" (Kirkpatrick \& Navarrete, 2006, p. 295).

Note that the terror management and coalitional relations perspectives differ not only in emphasis on the benefits of worldview defense but also with respect to the underlying psychological adaptation postulated as mediating worldview defense. According to coalitional psychology theory,

the central finding of terror management research - that participants in psychological studies who contemplate their corporeal death display greater support for the normative views of the ingroup — can be reinterpreted as an illustration of how individuals become more normative in their ideological orientation because of the benefits attending ingroup-affiliative behavior, [an adaptive function owing to] psychological mechanisms designed to increase normative mental representations that undergird the maintenance and formation of social relationships. (Navarrete \& Fessler, 2005, pp. 309-310)

Terror management theory rebuts the coalitional approach on evolutionary principles, arguing that

their proposed mechanism seems far too domain general, both in terms of its purported inputs and [affiliative] outputs, to be plausible as an evolved adaptation. In contrast, terror management theory posits a set of defenses to address a specific adaptive problem that has far-reaching consequences-the potential for debilitating anxiety resulting from awareness of the inevitable thwarting of one's life and virtually all one strives for. (Landau et al., 2007, p. 502)

As the above quotes demonstrate, the terror management and coalitional psychology accounts of worldview defense stress the domain-specificity of a hypothesized psychological adaptation engineered either to allay death anxiety or recruit allies by affirming cultural values. The unconscious vigilance account offers an elegant alternative: Worldview defense tokens the capacity to become sensitized to affective stimuli following subtle alarm. If so, then the worldview defense data accumulated over the past decades owe to an unconscious vigilance capacity that evolved irrespective of the domain of cultural attitudes but that is capable of influencing incidental evaluations of cultural attitudes to the extent that they inspire pleasant or aversive feelings.

Why consider unconscious vigilance an alternative to adaptationist explanations of the worldview defense effect? Some might argue, to the contrary, that the unconscious vigilance model actually complements adaptationist proposals by sketching in the proximal means through which terror management or coalitional psychology adaptations generate worldview defense to achieve their respective ultimate ends. This "distinct levels of description" view is misleading, however, because Darwinian adaptations are identified according to proximal mechanisms that possess discriminative design attributes precisely corresponding to their functions, like keys fitting locks (Tooby \& Cosmides, 2005; G. C. Williams, 1966). A broad class of subtle alarms may theoretically initiate unconscious vigilance, and subsequent evaluations of incidental affective targets may be biased whether or not they pertain to cultural attitudes. Therefore, interpreting worldview defense as simultaneously the result of unconscious vigilance and a psychological device specific to cultural attitudes and some narrow class of threats would violate the principle of domain-specificity used to distinguish genuine psychological adaptations from adaptive byproducts (Buss, Haselton, Shackelford, Bleske, \& Wakefield, 1998; Thornhill, 1997). 
The potential for usefulness to be mistaken for special design has been recognized since the inception of Darwinian theory, as Darwin himself illustrated:

The sutures in the skulls of young mammals have been advanced as a beautiful adaptation for aiding parturition, and no doubt they facilitate, or may be indispensable for this act; but as sutures occur in the skulls of young birds and reptiles, which have only to escape from a broken egg, we may infer that this structure has arisen from the laws of growth, and has been taken advantage of in the parturition of the higher animals. (Darwin, 1860, p. 220)

Like mammalian infant skull sutures, adaptive psychological traits may arise as by-products of structures that evolved for other reasons (Andrews, Gangestad, \& Matthews, 2002; Gould $\&$ Vrba, 1982). If a terror management or coalitional psychology adaptation has been designed to output increased investment in cultural values following reminders of death or the need for allies, then both the inputs to and outputs of the underlying architecture should evince domain-specificity: Only the postulated class of death or coalition-related threats should trigger worldview defense, and the inputs that trigger worldview defense should not polarize evaluations of affective targets unrelated to cultural values. The exact reverse holds for the claim that worldview defense is a by-product of unconscious vigilance: The alarm cues that produce worldview defense should not be limited to death or coalitional concerns, and they should foster biased evaluations of affective targets that are unrelated to cultural attitudes.

The uncertainty management construal of worldview defense differs from the claims of terror management theory or coalitional psychology in that the underlying psychological mechanism is proposed to respond to an unrestricted class of goal-conflicts (Inzlicht, McGregor, Hirsh, \& Nash, 2009; McGregor, 2006). According to uncertainty management theory, a phylogenetically ancient neural complex that evolved to enable goal-pursuit registers cues of personal uncertainty - or any other sort of poignant self-threat-as a goalconflict. Upon detecting a goal-conflict (e.g., a mortality-salience prime), this system is said to propagate goal-pursuit by mustering "defensive zeal" via connections with higher cortical centers, which represent personal convictions and worldview ideals as high-level personal goals (for a detailed account of this model, see McGregor, 2006). Given that a wide array of subtle threats that do not concern mortality have been shown to evoke worldview defense, uncertainty management theory concludes that "the common theme across the defensive outcomes may be more parsimoniously recognized as zeal than as symbolic immortality conferred by the successful adherence to cultural values" (McGregor, 2006, p. 302). Worldview defense, on this view, reflects the emphatic affirmation of personal goals to reduce the anxiety attendant to goal-conflict and to "re-engage feelings of hope and strength" (McGregor, 2006, p. 299). Such "zealously" polarized evaluations "may take the form of value convictions, communal commitment, closed-minded certainty, angry jingoism, religious fervor, or political extremism" because all of these expressions ostensibly strengthen representations of high-level personal goals (McGregor, 2006, p. 299).

Uncertainty management theory does not interpret worldview defense as the output of a mechanism uniquely evolved to strengthen cultural convictions, but rather as the product of a goal pursuit system co-opted to strengthen cultural convictions (qua high-level goals). Thus, although both the uncertainty management and unconscious vigilance models portray worldview defense as co-opting ancient processes that predate the development of "cultural worldviews" in homo sapiens, the hypothesized mechanisms are quite distinct. Uncertainty management theory casts worldview defense as a functional reengagement of goal-pursuit by affirming high-level goals, whereas the unconscious vigilance hypothesis casts worldview defense as a token example of enhanced sensitivity to incidental affective stimuli following background alarm. Accordingly, the unconscious vigilance model predicts that 
perceptions of valenced targets will be polarized in the aftermath of subtle alarm cues whether or not they pertain to cultural values or other high-level personal goals, whereas uncertainty management theory predicts that perceptions of targets unrelated to cultural values or personal goals should be irrelevant to the hypothesized goal-pursuit mechanism and therefore unaffected. Furthermore, the unconscious vigilance model is agnostic about whether exaggerating ratings of stimuli pertaining to cherished cultural values "defensively" alleviates anxiety.

As different as the three previous perspectives on worldview defense are, it should be acknowledged that each group has conceded that worldview defense might serve multiple functions or derive from multiple motivations (e.g., Landau et al., 2007; Navarrete, 2005; van den Bos et al., 2005). Regardless, all three theories propose adaptations either specifically designed (as terror management and coalitional psychology theory argue) or coopted (as uncertainty management theory argues) to exacerbate adherence to group values. Skeptical of these claims of a special relationship between certain unconscious threat cues and investment in cultural values, we resolved to test the input- output discriminativity of the mechanisms underlying worldview defense.

\section{Previous Attempts to Rule Out Explanations Such as Unconscious Vigilance}

A casual reading of the literature might suggest that the unconscious vigilance interpretation of worldview defense has already been ruled out by prior efforts to establish the domainspecificity of the underlying architecture. On the input side of the equation, for instance, terror management researchers have compared mortality-salience induction with manipulations involving aversive topics such as public speaking, failing important exams, or suffering intense dental pain, to test the alternative hypothesis that the threat-value associated with death engenders worldview defense rather than factors unique to the concept of death (Greenberg et al., 1997). These control manipulations lead participants to selfreport increased negative affect but do not induce worldview defense. Conversely, subtle death cues engender worldview defense but do not increase self-reported negative affect (Greenberg et al., 1995; Pyszczynski, Greenberg, \& Solomon, 1999). Analogously to mortality-salience manipulations, coalition primes (e.g., thoughts of social isolation) and uncertainty primes have engendered worldview defense without influencing self-report measures of affect (McGregor et al., 2001; Navarrete \& Fessler, 2006; Navarrete et al., 2004; van den Bos et al., 2005). Coalitional psychology theory draws on these findings to contest the terror management claim that only death-related manipulations evoke worldview defense, but it shares the basic terror management position that the role of indiscriminate threat-related affect (e.g., related to thoughts of failing an exam or delivering a public speech) has been ruled out. As Navarrete and Fessler (2005) argued,

contemplating failing an exam or having to give a speech should not be expected to provoke the same shifts in normative cognitions since these scenarios do not concern fitness-relevant challenges in which coalitions could conceivably be a part of an adaptive solution to the problem. (p. 308)

Thus, much as terror management theory posits the uniqueness of mortality-salience effects, the coalitional psychology perspective suggests that aversive prospects that do not implicate coalitional solutions should not inspire worldview defense.

Crucially, the terror management and coalitional psychology explanations of why aversive control primes fail to inspire worldview defense overlook the likelihood that awareness of conscious upset negates the influence of these manipulations. The self-reported distress associated with such control primes (e.g., imagining a painful dental procedure) indicates 
that the induction triggered emotion regulation likely to avert subsequent worldview defense bias. The notion that awareness of extraneous influences on one's feelings can diminish or negate bias is not controversial (Bodenhausen, Kramer, \& Süsser, 1994; Kehner, Locke, \& Aurain, 1993; Martin, Harlow, \& Strack, 1992). For example, Schwarz and Clore (1983) found that participants reported greater life satisfaction in telephone interviews when called on sunny versus rainy days, but that this effect was eliminated if the interviewer referenced the weather in a private aside, thus directing participants to recognize this unrelated affective influence. On the other hand, individuals are more likely to produce biased evaluations of incidental targets following affective primes when unaware of having been influenced (for reviews, see Loewenstein \& Lerner, 2003; Pham, 2007; Schwarz \& Clore, 2007;

Winkielman, Knutson, Paulus, \& Trujillo, 2007). In fact, entirely unconscious valenced stimuli can influence judgments of liking or disliking without arousing awareness of emotional influence (for reviews, see Winkielman \& Berridge, 2004; Winkielman, Berridge, \& Wilbarger, 2005a). These precedents indicate that, absent awareness of their influence, aversive cues unrelated to death or coalitional relations may indeed initiate unconscious vigilance and potentiate worldview defense.

On the output side of the equation, the unconscious vigilance model indicates that a wide array of emotional targets should be evaluated with bias whether or not they relate to cultural attitudes. In one of the earliest worldview defense studies, Rosenblatt, Greenberg, Solomon, Pyszczynski, and Lyon (1989, Study 4) anticipated and tested the possibility that worldview defense reflects heightened sensitivity to affective valence rather than cultural ideologies in particular. In apparent support of the discriminative validity of worldview defense, they found that ratings of activities such as "getting a good night's sleep" or "sitting through a boring lecture" were not biased by mortality-salience. Nevertheless, and as the researchers openly acknowledged, this finding may have resulted from participants' lack of engagement with the target items: Reading an ostensibly genuine derogation or praising of one's group seems likely to evoke a greater emotional reaction than pale phrases such as "getting a good night's sleep."

To follow-up on the possibility that some form of implicit arousal drives worldview defense rather than a dedicated terror management mechanism, Rosenblatt et al. (1989, Study 5) next tested pulse rate, pulse volume, and skin conductance after inducing mortality-salience, and again they found no significant effects. However, this null result is actually in line with observed dissociations between neural and autonomic reactions to threat. L. M. Williams et al. (2006), for example, observed that exposure to subliminal fearful faces correlated with activation of the amygdala and the anterior cingulate but not with increases in skin conductance amplitude (also see Whalen et al., 1998). In direct support of the notion that subtle death cues trigger unconscious threat reactions, Arndt, Allen, and Greenberg (2001) correlated subliminal exposure to the word "dead" with rapid flashes of implicit negative affect using facial electromyography. These findings suggest that unconscious threatdetection produces a relatively subtle bodily response, just as one might expect given the consistent lack of self-reported negative affect following mortality-salience induction. Indeed, it would be strange for participants who self-report no conscious changes in affect to evince notable changes in heart rate, blood pressure, or perspiration, because such bodily cues are in themselves largely constitutive of subjective emotional experience (Prinz, 2004).

In sum, unconscious vigilance remains a plausible explanation of the psychological process at play given the insufficiency of previous attempts to establish the discriminative validity of either the eliciting primes or worldview defense itself. The subtle threat manipulations used in worldview defense research may trigger a state of intensified reactivity to valenced stimuli, precipitating polarized evaluations of a wide range of pleasant and aversive targets 
provided that participants are unaware of having been influenced. If so, worldview defense would number among indefinitely many token expressions of unconscious vigilance bias.

\section{Testing Unconscious Vigilance}

If, as terror management theory and coalitional psychology propose, there is a psychological adaptation functionally designed to trigger worldview defense upon detection of death cues, then mortality-salience should not exaggerate evaluations of stimuli devoid of ideological significance (Rosenblatt et al., 1989). Likewise, mortality-salience should not bias ratings of targets unrelated to cultural attitudes if, as argued by uncertainty management theory, worldview defense bias reflects a special motivation to affirm cultural convictions following poignant self-threats (McGregor, 2006). On the contrary, if death cues influence judgment because of unconscious vigilance, then mortality-salience should polarize evaluations of valenced stimuli that are unrelated to cultural worldviews. To test the unconscious vigilance hypothesis, mortality-salience was induced prior to presentation of pleasant and aversive worldview-neutral sounds (Study 1) and images (Study 2), rather than the flattering and critical essays about participants' in-groups used in standard worldview defense research (e.g., Greenberg, Pyszczynski, Solomon, Simon, \& Breus, 1994).

Just as the influence on affective evaluation targets should be indiscriminate, the unconscious vigilance model predicts that unconscious threats should elicit worldview defense whether or not they relate to death or coalition-implicating challenges. Therefore, in Studies 3 and 4, we exposed participants to subliminal cues of death or more general threats while maintaining the dependent measures of the standard worldview defense task.

\section{Study 1 \\ Method}

Participants-Forty-three undergraduate students from Queen's University Belfast were recruited to participate in exchange for $£ 4$ (approximately $\$ 7$ at the time of the study) compensation. Two outliers of approximately $2 S D$ s from the mean of the main dependent variable were excluded from the analyses (Kirk, 1995), leaving a sample of 31 women and 10 men, ranging in age from 18 to 23 years $(M=20.05, S D=1.46)$.

Materials and procedure-Participants were escorted into the laboratory and told they would be helping to pilot test several unrelated measures for use in future research. Participants were seated in individual cubicles and tested in groups ranging in size from one to three. All materials were presented via computer using the program Inquisit 3.0.1.0 (Millisecond Software, 2008), which randomly assigned participants to either the mortalitysalience condition or the control (television-salience) condition.

Following an initial demographic survey, participants completed two filler scales. Next, participants in the mortality-salience condition were asked to respond to prompts commonly used in terror management studies (e.g., Rosenblatt et al., 1989): (a) "Please briefly describe the emotions that the thought of your own death arouses in you," and (b) "Please jot down, as specifically as you can, what you think will happen to your body as you physically die and once you are physically dead." Control participants were asked parallel questions about watching television (Harmon-Jones et al., 1997).

Following the standard worldview defense procedure, participants completed the Positive and Negative Affect Scales_Expanded Form (PANAS-X; Watson, \& Clark, 1991) after the mortality-salience manipulation. The PANAS-X measures consciously accessible affect by asking participants to rate the extent to which they feel 60 affective states, with subscales 
assessing general negative and positive affect as well as specific negative emotions (fear, hostility, guilt, sadness), positive emotions (joviality, self-assurance, attentiveness), and other affective states (shyness, fatigue, serenity, and surprise). This measure also provides a period of distraction and delay to decrease conscious awareness of the influence of the mortality-salience manipulation (Greenberg et al., 1994).

For the dependent measure, participants were asked to rate two 6-s sounds. Analogously to the positive and negative essays used in worldview defense research, one sound was intended to be considered pleasant, and one was intended to be aversive. The sounds were selected through pilot testing of eight pleasant and aversive sounds created by the first author on the basis of his intuition. The pilot results indicated that of the initial array of sounds, these two would be consistently experienced by participants as moderately pleasing and displeasing in the intended pattern. The aversive sound was an abrupt burst of pink noise. The pleasant sound was generated electronically using harmonious synthesized tones and reverb. Sounds were presented in counterbalanced order at a loud but comfortable volume using headphones. Following each sound, participants were asked to respond to two questions: "How much do you like this sound?" and "How much would you like to hear this sound again?" Participants answered using a 9-point Likert scale $(1=$ not at all, $9=$ extremely).

After the experiment, each participant was questioned for suspicion about the purpose of the study and then received a debriefing and compensation. No participant evinced suspicion that the manipulation and the sound evaluations were related.

\section{Results}

Sound evaluations-The two rating items were internally reliable for both the pleasant sounds (Cronbach's $a=.80$ ) and the aversive sounds (Cronbach's $a=.81$ ). To compute participants' overall rating of each sound, the two ratings were averaged. In previous terror management experiments, worldview defense has been calculated by subtracting the mean rating of the author of a negative essay from the mean rating of the author of a positive essay (e.g., Greenberg et al., 1994). Similarly, we calculated sound bias by subtracting the mean rating of the aversive sound from the mean rating of the pleasant sound for each participant. Mean sound bias in the mortality-salience condition was greater than in the control condition (see Table 1). The difference in sound bias reached statistical significance, $F(1,39)=4.84, p$ $<.04, \eta^{2}=.11$. There were no significant effects of age, gender, or order of sound presentation.

Self-reported affect-A multivariate analysis of variance performed on the 13 subscales of the PANAS- $X$ revealed no significant effects of condition. In addition, an analysis of variance on the difference between positive and negative affect revealed no effect.

\section{Discussion}

Study 1 modified a standard procedure used to investigate worldview defense by presenting pleasant and aversive sounds in place of flattering or critical essays about participants' ingroups. The results support the unconscious vigilance perspective. As predicted, the death manipulation significantly biased judgments of the sound stimuli without influencing selfreported affect. To the extent that aesthetic preferences for and against abstract sounds do not constitute "defensive" affirmations of one's cultural convictions, this result is at odds with terror management, coalitional psychology, or uncertainty management theories of worldview defense. However, the possibility remained that this finding was somehow an artifact of the particular sounds employed, or of the domain of sound. To further establish 
the generality of the influence of mortality-salience on the evaluation of valenced stimuli, we employed worldview-neutral image targets in Study 2.

Representational images were used in Study 2 to counter an anticipated terror management objection to the abstract, nonrepresentational sounds employed in Study 1. In previous research on the influence of death cues on judgments of abstract expressionist paintings, terror management theorists claimed that reminders of death exacerbate the need for meaningfulness that worldviews ostensibly provide but that nonrepresentational art obscures (Landau, Greenberg, Solomon, Pyszczynski, \& Martens, 2006). Indeed, they found that mortality-salience led to greater aesthetic dislike of nonrepresentational art-a finding that terror management investigators have cited as supportive but that we interpret as illustrative of the arbitrariness of the valenced stimuli susceptible to evaluation bias. In Study 2, to control for representation, participants rated valenced photographs of real-world scenes that did not flatter, disparage, or particularly relate to cultural worldviews.

\section{Study 2}

\section{Method}

Participants—Forty-eight participants were recruited for an online study on "Personal Attitudes \& Perceptions" in exchange for inclusion in a raffle of $£ 10$ (approximately $\$ 13$ at the time of the study) Amazon.com gift certificates, with a one in 10 chance of winning.4 One outlier of approximately $2 S D$ s from the mean of the main dependent variable was excluded from the analyses (Kirk, 1995), leaving a sample of 34 women and 13 men, ranging in age from 18 to 65 years $(M=34.53, S D=12.85)$.

Materials and procedure-Participants were initially asked to select a button on the basis of correspondence to the last letter of their last name. This selection assigned them to either the mortality-salience condition or the control condition. The subsequent demographic questions, filler scales, death or television manipulations, and PANAS-X measures were identical to those used in Study 1. All materials were presented using SurveyMonkey (Finley, 2008).

For the dependent measure, participants were asked to rate two images, presented in counterbalanced order. Like the sounds used in Study 1, one image was intended to be considered pleasant, and one was intended to be considered aversive. The images were selected through pilot testing of 14 intuitively pleasant and aversive images selected by the first author. The pilot results indicated that these two images would be consistently experienced as moderately pleasing and displeasing in the intended pattern. The aversive image was of a hallway with a lightly stained carpet; the pleasant image was of a mountain lake. Participants were asked to rate their agreement to three statements about each image: "I like this image," "I want to see more images like this," and "I would like to be there." Participants answered using a 9-point Likert scale $(1=$ very strongly disagree, $9=$ very strongly agree).

At the close of the study, participants were asked what they thought the researchers were expecting to find, and whether they recognized any questions from previous studies. No participant evinced suspicion that the mortality-salience manipulation and the image evaluations were related. Participants were thanked and debriefed on the final page.

\footnotetext{
${ }^{4}$ Previous pilot testing as well as Study 1 demonstrated that participants required a minimum of $10-15$ min to complete these materials. Therefore, to ensure that our online participants were attending appropriately, we explicitly stated that participants should adopt a moderate pace, which would take approximately $15 \mathrm{~min}$ to complete. We then filtered the responses to exclude those who had completed the study in less than $10 \mathrm{~min}$.
} 


\section{Results}

Image evaluations-The three rating items were internally reliable for both the pleasant images (Cronbach's $a=.96$ ) and the aversive images (Cronbach's $a=.86$ ). To compute participants' overall evaluation of each image, the three ratings were averaged. Image bias was calculated by subtracting the average rating of the aversive image from the average rating of the pleasant image for each participant. Mean image bias in the mortality-salience condition was greater than in the control condition (see Table 1). The difference in image bias was significant, $F(1,45)=5.02, p<.03, \eta^{2}=.10$. There were no significant effects of age, gender, or order of image presentation.

Self-reported affect-A multivariate analysis of variance performed on the 13 subscales of the PANAS-X revealed no significant effects of condition. In addition, a separate analysis of variance on the difference between positive and negative affect revealed no effect.

\section{Discussion}

Study 2 modified Study 1 by testing the influence of mortality-salience on ratings of worldview-neutral images rather than sounds. As predicted by the unconscious vigilance model, mortality-salience led to exaggeratedly contrastive evaluations of pleasant versus aversive images. Studies 1 and 2 indicate that death cues bias judgments of incidental affective stimuli on the basis of the intensified feelings that the stimuli elicit rather than their ideological content. These results indicate that cultural convictions are important for the worldview defense effect only to the extent that they imbue evaluation targets with affective valence.

\section{Study 3}

The results of Studies 1 and 2 illustrate the indiscriminativity of the influence of mortalitysalience on evaluations of valenced targets, supporting the unconscious vigilance model. We turned next to testing the discriminativity of the input primes that may produce worldview defense. Previous researchers have established that nondeath manipulations (e.g., reminders of social isolation, robbery or feeling uncertain) create worldview defense without heightening accessibility to thoughts of death (McGregor et al., 2001; Navarrete et al., 2004; van den Bos et al., 2005). Nevertheless, entirely unconscious, subliminal death cues have been shown to produce worldview defense when compared with aversive, nondeath control cues (Arndt et al., 2001; Arndt, Greenberg, Pyszczynski, \& Solomon, 1997; Dechesne, Janssen, \& van Knippenberg, 2000; Dechesne et al., 2003). To test the discriminativity of death cues at a subliminal level of processing, therefore, subliminal death and nondeath stimuli were manipulated in Study 3.

The amygdala, an integral structure for vigilance to environmental threats (LeDoux, 1996; Liddell et al., 2005; Whalen et al., 1998), responds more strongly to emotive faces than to other covertly presented emotional stimuli (Hariri, Tessitore, Mattay, Fera, \& Weinberger, 2002). We therefore exposed participants to subliminal threatening face stimuli to employ a previously validated way of inducing unconscious threat-detection in neural regions implicated by the unconscious vigilance model.

\section{Method}

Participants-One hundred and forty-seven participants were recruited online to complete a "5-Minute Study on Gender Identification and Social Attitudes." Participation was unpaid and available only to American citizens over 18 years of age. As a manipulation check, worldview defense studies typically screen participants whose worldview orientation would not be relevant (e.g., Greenberg, Arndt, Schimel, Pyszcznski, \& Solomon, 2001; Navarrete 
et al., 2004). In this online study, we established worldview orientation by filtering out participants who rated the anti- U.S. author more highly than the pro-U.S. author. For the same reason, we removed participants who reported that they were of Latin American descent, because the target essays involved Latin American immigrants who were intended to be out-group members from the point of view of the participants. Participants who made errors during the easy task that masked the subliminal manipulation were removed from analysis because of suspicion that they were not paying attention. Two outliers of approximately $3 S D$ s from the mean of the dependent variable were also removed (Kirk, 1995). This left a sample of 67 women and 25 men, ranging in age from 18 to 60 years $(M=$ 25.28, $S D=8.93$ ). Of the participants, $72.8 \%$ identified as White, $10.9 \%$ identified as Black, $5.4 \%$ identified as Asian, and $10.9 \%$ identified as other.

Procedure-After obtaining demographic information, participants were asked to classify a series of faces according to gender. This task actually provided an opportunity to subliminally prime participants with four randomly assigned between-subjects conditions: positive cue (happy faces), threat cue (angry faces), death cue (skulls), and control (neutral faces).

Modifying a procedure used by Winkielman, Berridge, and Wilbarger (2005b), the subliminal face images were embedded between the plainly visible neutral faces of men and women used in the gender identification task. Angry faces were used as negatively valenced stimuli associated with threat but not particularly related to death. Happy faces were presented as an exploratory test of whether cues of reward would influence participants' author evaluations.5 The subliminal and supraliminal face stimuli were taken from the Japanese and Caucasian Facial Expressions of Emotion (JACFEE; Matsumoto \& Ekman, 1988) set and converted to gray-scale. In addition, images of a subliminal skull of the same color and dimensions as the faces were presented as the mortality-salience manipulation. The skull image was formatted to match the background of the JACFEE set. All materials were presented using the software platform Inquisit 3.0.1.0 (Millisecond Software, 2008).

The gender classification task consisted of a practice block and an experimental block of eight trials each. The experimental block consisted of eight priming trials because previous research has found eight trials to maximally activate the amygdala without inducing habituation (Whalen et al., 1998; Winkielman et al., 2005b). During the practice block, subliminal neutral faces were interpolated between the visible neutral faces. Each trial began with a forward mask (a cross shape) presented for 50-ms, followed by a 32-ms subliminal image, followed by a plainly visible male or female face as the backward mask (see Figure 1). The visible male or female face remained on the screen until the participant entered a gender classification response, at which point the next trial immediately commenced. The visible faces never repeated-16 different male and female neutral faces were presented in random order, divided evenly by gender and ethnicity. The subliminal experimental sequences presented one repeated skull image or four different angry, happy, or neutral (control) faces, randomized within valence. Only one skull image was formatted for subliminal presentation because forward-facing skulls appear nearly identical.

After the gender identification task, participants were asked to read two essays ostensibly written by immigrants from Latin America. The text for these essays was taken directly from previous terror management research (e.g., Greenberg et al., 1990). One essay was

\footnotetext{
${ }^{5}$ The only instance of a potential positively valenced prime previously used in worldview defense research that we are aware of is Carlos Navarrete's (2005) cooperative house-building prime presented in a study conducted in rural Costa Rica. However, although this manipulation was intended to be positively valenced, it is unclear just what the unconscious affective response of the participants may have been to the prospect of soliciting their community for help to build a new house.
} 
complementary toward the United States and the other was critical. The essays were presented in counterbalanced order as photos of handwritten paragraphs (Arndt et al., 2001).

After reading each essay, participants were asked to rate its author according to a modified version of the Interpersonal Judgment Scales (IJS; Byrne, 1971), which has been adopted for use in previous worldview defense research (e.g., Greenberg et al., 2001; Navarrete \& Fessler, 2006; Navarrete et al., 2004). Participants clicked one of nine horizontally displayed buttons with their mouse to rate their agreement with the following seven statements about each author on a 9-point Likert scale $(1=$ not at all, $9=$ extremely): (a) "This person is likable," (b) "This person is intelligent," (c) "This person is well-informed," (d) "This person is moral," (e) "This is the kind of person I would like to work with," (f) "This person is honest," and (g) "This person is well-adjusted."

Following the author ratings task, suspicion was checked by asking participants to provide any ideas they had about the intent of the experiment. As a manipulation check, participants were also asked whether they noticed any hidden or subtle images during the gender identification task. If so, they were asked to describe what they may have observed. No participant evinced suspicion of the actual intent of the study or that covert images were embedded within the gender identification task. Finally, participants were thanked, debriefed, and encouraged to forward the study to any American citizen over the age of 18 years whom they thought would be interested.

\section{Results}

Author evaluations-The seven IJS ratings items were internally reliable (Cronbach's a $=.85$ for both the pro-U.S. author and the anti-U.S. author). Following previous terror management analyses, worldview defense was computed by subtracting the mean rating of the anti-U.S. author from the mean rating of the pro-U.S. author (e.g., Greenberg et al., 1994). Planned contrasts between the neutral condition and each of the experimental conditions revealed that only exposure to subliminal angry faces led to a statistically significant increase in worldview defense, $F(1,47)=4.54, p<.04, \eta^{2}=.09$ (see Table 2). The happy face and skull manipulations did not show significant effects on author ratings $(p s>.3)$. There were no significant effects of age, gender, ethnicity, or order of presentation.

\section{Discussion}

Whereas Studies 1 and 2 tested the scope of the outputs of the process responsible for worldview defense, we reversed tactics in Study 3 by testing the generality of the input variable. We predicted that both the angry face and skull manipulations would lead to worldview defense; the happy face manipulation was introduced as an exploratory test of the influence of unconscious cues of reward.

As predicted, exposure to subliminal angry faces evoked worldview defense, a finding that is consistent with unconscious vigilance but that contradicts terror management theory. Although previous studies have also demonstrated that worldview defense reliably follows nondeath manipulations (e.g., Navarrete, 2005; Navarrete et al., 2004; van den Bos et al., 2005), this is the first time that an aversive nondeath cue has been shown to evoke worldview defense via a subliminal pathway. This result is consistent with the coalitional psychology interpretation of worldview defense, as angry faces obviously cue a fitnessrelevant threat better resolved with social aid. Nonetheless, the coalitional perspective cannot readily account for the indiscriminative bias of worldview-neutral sound and image targets observed in the first two studies. 
Unexpectedly, participants in the skull condition did not exhibit worldview defense. The failure of the skull manipulation to exaggerate bias was surprising considering that subliminal presentation of the words "death" or "dead" have previously promoted worldview defense (Arndt et al., 2001; Arndt, Greenberg, Pyszczynski, \& Solomon, 1997; Dechesne et al., 2000) and have been correlated with flashes of negative affect measured with facial electromyography (Arndt et al., 2001). However, given that the amygdala responds primarily on the basis of eye contours (Whalen et al., 2004), the subliminal skull images were likely processed as emotionally ambiguous or neutral because of their circular eye sockets. Additionally, it is possible that the participants had become so habituated to the omnipresent skull imagery present in contemporary media and fashion (Cassutt, 2008) that the subliminal skulls harbored insufficient alarm connotations.

The lack of evaluation bias following happy face priming was not unexpected, considering that previous studies of worldview defense have almost uniformly used threatening primes. Nevertheless, if happy faces were processed by alarm mechanisms as salient reward cues, then the happy face manipulation might be expected to facilitate worldview defense. However, happy faces are relatively pale reward cues relative to, for instance, erotic imagery. Moreover, the amygdala responds with less activation and quicker habituation to happy versus fearful subliminal face stimuli (Whalen et al., 1998; Wright et al., 2001), which may at least partly account for the present null result. Thus, as explored further in the General Discussion, we do not interpret the present finding as compelling evidence against the potential influence of stronger reward cues on worldview defense.

\section{Study 4}

Study 3 supported the unconscious vigilance prediction that a threat cue unrelated to death (angry faces) would promote worldview defense bias. However, the failure of the skull manipulation to engender bias prevented comparison of the relative influence of exposure with subliminal death and nondeath threat stimuli. Study 4 was designed to amend this shortcoming and to duplicate Study 3 in a different subliminal modality. In addition, Study 4 was intended to test whether a threat cue without a specific conceptual link to coalitionrelevant problems would produce worldview defense.

In previous studies of the effects of implicitly induced mortality-salience, Jamie Arndt and colleagues (Arndt et al., 2001; Arndt, Greenberg, Pyszczynski, \& Solomon, 1997; also see Dechesne et al., 2000, 2003) presented subliminal sequences of either the word "dead" or the word "pain" before a worldview defense measure. In these experiments, exposure to "dead" elicited greater pro-U.S. bias than exposure to "pain," suggesting that the word "dead" carries a stronger negative connotation than "pain" when presented subliminally. Notably, in the original terror management research series, subliminal "pain" fostered greater pro-U.S. bias than subliminal "field," which was used as an affectively neutral control manipulation in a nearly identical study (Arndt, Greenberg, Pyszczynski, \& Solomon, 1997). Had they statistically compared the influence of exposure to subliminal "pain" versus "field," we speculate that they may indeed have found a worldview defense effect caused by the "pain" manipulation. If unconscious vigilance underlies worldview defense, then unconscious threat manipulations should elicit the effect whether or not they pertain to death or coalitional relations. Thus, subliminal presentations of the words "dead" and "pain" should both evoke worldview defense relative to "field," with "dead" producing greater bias as the more aversive prospective threat. Study 4 tested these predictions.

\section{Method}

Participants-Two hundred and seventy-seven participants were recruited online to complete "Two Mini-Studies: Meaning Matching and Cultural Attitudes" in exchange for 
inclusion in a raffle of $\$ 10$ Amazon.com gift certificates, with a one in 10 chance of winning. Participation was available only to U.S. citizens over 18 years of age. The criteria for inclusion were identical to those used in Study 3. Six outliers of approximately $3 S D$ s from the mean of the dependent variable were also removed (Kirk, 1995). This left a sample of 126 women and 65 men, ranging in age from 18 to 67 years $(M=33.17, S D=11.98)$. Of the participants, $75 \%$ identified as White, $4.7 \%$ identified as Black, $10.5 \%$ identified as Asian, and $9.4 \%$ identified as other.

Procedure-Following demographic questions, participants were asked to perform a task in which they classified pairs of words as meaningfully related or not. This task actually provided an opportunity to subliminally prime participants with one of three randomly assigned lexical manipulations: "field," "pain," or "dead." Modifying a procedure used by Arndt, Greenberg, Pyszczynski, and Solomon (1997), the subliminal words were embedded between plainly visible words used in the semantic relations task. For each trial, two words were flashed sequentially on the computer. Participants then pressed either the "Q" or "P" key to signify that the words were related or not related, respectively. For example, if they saw the pair pencil and paper, they were to press the "Q" key, but if they saw such pairs as tuxedo and forest, they were to press the "P" key. All materials were presented using the software platform Inquisit 3.0.1.0 (Millisecond Software, 2008).

The semantic relations task consisted of a practice block and an experimental block of 10 trials each, following Arndt, Greenberg, Pyszczynski, and Solomon (1997). During the practice block, subliminal letter strings (e.g., "adbc") were interpolated between the visible words. Each trial began with a 1,000-ms pause, followed by the first word of the pair presented for $428 \mathrm{~ms}$, followed by the subliminal word presented for $32 \mathrm{~ms}$, followed by the second word presented for $428 \mathrm{~ms}$. The next trial commenced as soon as the participant entered his or her response. The related and unrelated word pairs were presented in random order and were never repeated.

After the semantic relations task, participants were asked to complete the same author ratings task used in Study 3. Following the author ratings task, suspicion was checked by asking participants to provide any ideas they had about the intent of the experiment. No participant evinced suspicion that the semantic relations task and the author ratings were experimentally related. As a manipulation check, participants were also asked to describe any "glitches" or "unexpected aspects" observed during the semantic relations task. Next, they were asked to state whether they had or had not observed any hidden words during the task, and then were asked to select which of the following words may have been disguised: field, hurt, love, dead, food, numb, sex, and pain. Finally, participants were thanked, debriefed, and encouraged to forward the study to any U.S. citizen over the age of 18 years whom they thought would be interested.

\section{Results}

Author evaluations-The seven IJS ratings items were internally reliable (Cronbach's a $=.91$ for the pro-U.S. author, Cronbach's $a=.94$ for the anti-U.S. author). Worldview defense was again computed by subtracting the mean rating of the anti-U.S. author from the mean rating of the pro-U.S. author. Planned contrasts revealed that both experimental manipulations significantly increased pro-U.S. bias (see Table 3). Subliminal "pain" induced worldview defense, $F(1,144)=3.93, p<.05, \eta^{2}=.03$; subliminal "dead" induced worldview defense, $F(1,100)=10.61, p<.01, \eta^{2}=.11$. There were no significant effects of age, gender, ethnicity, or order of presentation. 
Manipulation checks-Of the participants, $98.4 \%$ did not report any glimpses of hidden content during the semantic relations task when asked in an open-ended question. Next, when directly asked whether they believed that they may have been exposed to any hidden words or messages, $62.3 \%$ of participants selected "No." Of the minority who selected "Yes," $19.7 \%$ correctly selected the word that was subliminally presented from a list of eight options; $14.7 \%$ of total participants correctly guessed which of the eight words they were subliminally exposed to.

\section{Discussion}

As predicted, both the subliminal "pain" and "dead" manipulations led to worldview defense, supporting the unconscious vigilance hypothesis but challenging the terror management claim that subliminal mortality-salience inductions generate worldview defense uniquely. Furthermore, the degree of experimentally induced pro-U.S. bias adhered to the predicted pattern, with "dead" producing the highest level of bias and "pain" intermediate between "dead" and "field." The "pain" manipulation exhibited a notably weak effect relative to the robust "dead" manipulation. The disproportionate influence of the two primes is consistent with the commonsense notion that implicit cues of death are more threatening than cues of pain, and may explain how contrasts of implicit "pain" manipulations and "dead" manipulations have produced significant differences in previous terror management studies.

Whereas Study 3's implicit threat manipulation, angry faces, qualified as a coalitional prime, the subliminal word "pain" does not designate a circumstance implicative of a need for coalitional aid in particular. Thus, the results of Study 4 are difficult to reconcile with the coalitional interpretation of the computational mechanisms supposed to produce worldview defense. Study 4 also supports the unconscious vigilance hypothesis by extending Study 3's finding that subliminal nondeath face primes can engender worldview defense to an alternate modality.

\section{General Discussion}

We found support for the unconscious vigilance hypothesis across four studies. Studies 1 and 2 demonstrate that mortality-salience biases judgments of worldview-neutral sounds and images, contradicting the discriminative validity of worldview defense as the output of a system designed to increase adherence to cultural values. When taken together, Studies 3 and 4 show that subliminal threats unrelated to death or coalition-relevant problems can evoke worldview defense. In the concluding discussion, the implications of these findings for functional perspectives on worldview defense are examined, followed by directions for future background alarm, evaluation bias, and emotion regulation research.

\section{Implications for Evolutionary Accounts of Worldview Defense}

The present results challenge all three prior evolutionary interpretations of worldview defense. Terror management theory and coalitional psychology characterize worldview defense as the output of a functional adaptation designed to allay death anxiety or recruit allies by exacerbating commitment to cultural values, but our studies show that the inputs to the underlying process transcend death or coalitional concerns, and the outputs transcend the domain of cultural values. Worldview defense therefore appears better explained as a byproduct of unconscious vigilance than as the output of a terror or coalition management adaptation.

The tensions between the present findings and the uncertainty management framework are more subtle. Uncertainty management theory portrays worldview defense as a "zealous" 
affirmation of cultural convictions (i.e., high-level personal goals), but Studies 1 and 2 found that mortality-salience elicits exaggerated ratings of sound and image targets unrelated to cultural convictions. Nonetheless, seeking pleasing and avoiding displeasing noises or sights could be considered the pursuit of concrete, low-level goals that have no particular connection to cultural values or identity, but that nonetheless derive from the anxietyreduction/goal-pursuit system described by uncertainty management theory (McGregor, 2006). Furthermore, producing exaggerated ratings of valenced targets when unconsciously vigilant may reduce anxiety, or at least discharge the state of background alarm (which may or may not be aptly conceptualized as a form of low-level anxiety), much as argued within uncertainty management theory. If unconscious vigilance evolved to facilitate conscious identification of the environmental element that initially triggered the state of background alarm, then encountering affectively weighted (i.e., significant) stimuli could signal that the vigilance elicitor has been identified, ending the state of alarm. If so, then the unconscious vigilance account could be compatible with a construal of uncertainty management theory that does not emphasize the relevance of deeply held personal convictions, cultural ideals, or other high-level goals to evaluation bias (also see van den Bos et al., 2008).

Looking ahead, however, the uncertainty management premise that a goal-conflict detection mechanism triggers worldview defense remains at odds with our model of unconscious vigilance, which may be theoretically initiated by subtle alarm cues that do not involve goalconflicts. Although our presentation and present findings have focused on threats (i.e., goalconflicts), the neuroscience data on background alarm indicate that subtle cues of salient rewards may also engage unconscious vigilance. The amygdala responds to unconscious affective stimuli of positive as well as negative valence (Adolphs, 2008; Adolphs, Russell, \& Tranel, 1999; Davis \& Whalen, 2001); erotic imagery, for instance, has been shown to trigger amygdala reactivity without conscious awareness (Jiang, Costello, Fang, Huang, \& $\mathrm{He}, 2006$ ). Likewise, subtle alarm cues such as background blinking lights or exclamation marks that have previously swayed responses to injustice (van den Bos et al., 2008) may initiate unconscious vigilance without designating goal-conflicts so much as a need for accentuated attention. For the moment, however, this distinction between uncertainty management and unconscious vigilance predictions remains theoretical. Further research is required to ascertain the range of alarm cues that activate incidental evaluation biases such as worldview defense.

The evolutionary origins of unconscious vigilance are also unclear at present. Unconscious vigilance might be an adaptation designed to marshal identification of and responsiveness to background hazards or resources. Alternatively, this capacity may have arisen as a useful by-product of more encompassing systems, such as those evolved to facilitate executive task-shifting from current focal objectives to new environmental demands. Ultimately, the domain-specificity of the unconscious vigilance system must be empirically delineated before functional design may be surmised. For example, are there particular types of incidental affective targets that are immune to unconscious vigilance evaluation bias? Our current results only show that unconscious detection of threat cues polarizes evaluation of an array of affective targets, which can but need not relate to cultural values.

\section{Worldview Defense as a Secondary Adaptation?}

The unconscious vigilance dynamic explains exaggerated reactions to polarizing cultural attitudes, but other complex conceptual processes are involved in forming cultural attitudes that people relate to emotionally. Suppose, for the sake of argument, that worldview defense indeed arose as a useful by-product of unconscious vigilance (e.g., which enabled persons exposed to subtle threats in the ancestral past to better recruit allies, as argued within coalitional psychology theory). Natural selection might have subsequently elaborated the relationship between unconscious vigilance structures and social cognitive mechanisms 
supporting investment in cultural values, thereby enhancing the link between a subset of inputs (e.g., coalitionally relevant threats) and outputs (e.g., displays of heightened cultural chauvinism). If so, worldview defense would qualify as a secondary adaptation, much as a proto-feather adaptation for thermal regulation in birds has been proposed by some to have been selectively refined and repurposed for flight (Gould \& Vrba, 1982).

At present, however, there are no evident grounds for supposing that such selective tinkering occurred. As G. C. Williams (1966) prescribed, "an effect should be assumed to be the result of physical laws only, or perhaps the fortuitous effect of some unrelated adaptation, unless there is clear evidence that it is produced by mechanisms designed to produce it" (p. 261). There is currently no direct evidence for or against the claim that heightened cultural normativity following subtle threat actually increases fitness, but future debates may involve ascertaining the circumstances in which unconscious vigilance generates fortuitous effects related to affirming cultural worldviews. To the extent that worldview defense is eventually determined to enhance fitness, it should be classified as an exaptation; to the extent that worldview defense is found not to increase fitness, it should be classified as noise (Buss et al., 1998; Gould \& Vrba, 1982).

\section{Beyond Worldview Defense: Individual Differences and Related Biases}

We set out to test the discriminative validity of worldview defense, not the litany of effects reported by terror, coalition, and uncertainty management researchers. To the extent that we present our results as problematic for previous theories, however, we are obliged to propose ways of theoretically reconciling our model with their wider data. The discussion that follows is a preliminary effort to do so, tendered as no more than a plausible reframing of individual difference effects on worldview defense and related biases as they might be explicated in terms of unconscious vigilance.

Terror management researchers have investigated the effects of mortality-salience on an array of ratings and behaviors, including aggression, ethnocentrism, political conservatism, legal penalties, social stereotyping, and aesthetic preferences (see Table 4). In addition, a number of experimentally manipulated or personality-based individual difference variables (e.g., self-esteem, authoritarianism) have been found to influence mortality-salience induced biases (for a review, see Landau et al., 2007). Largely parallel individual difference results have been reported by coalitional psychology and uncertainty management investigators (e.g., McGregor, Haji, Nash, \& Teper, 2008; McGregor, Nash, \& Inzlicht, 2009; Navarrete, 2005). The individual difference effects on worldview defense (and related biases) are formidably diverse, but all seem to direct or nullify bias according to a straightforward rubric: individually and culturally varying emotional investment in the primes or the targets.

On the prime side of the equation, the degree of threat connoted by a given topic depends on the affective threat-index associated with it (Adolphs et al., 1999). When the prime involves death, for example, a person who perceives death as less distressing should be less susceptible to mortality-salience effects. Indeed, religiosity has been observed to reduce or eliminate mortality-salience effects among populations whose religious views prefigure secure afterlives (Jonas \& Fischer, 2006; van den Bos, van Ameijde, \& van Gorp, 2006) but not populations whose religious doctrines prefigure perilous afterlife experiences (Holbrook, 2011). Self-esteem appears, like religiosity, to calibrate the degree of perceived threat. For example, Greenberg et al. (1993) observed that high self-esteem reduced galvanic skin response to the threat of an imminent electric shock. High self-esteem is also related to approach-motivation, which neurological, behavioral, and self-report studies have correlated with reductions in the startle-reflex and negative reactions to aversive stimuli (McGregor et al., 2009). Threatmitigators such as self-esteem and religiosity may ameliorate threat-value, explaining why these individual differences have been observed to reduce worldview 
defense following a wide range of death, coalitional threat, and uncertainty primes (Greenberg, 2008; Navarrete, 2005).

However, self-esteem does not always mellow defensive reactions. When the evaluation target directly relates to the basis of a person's self-esteem, then self-esteem actually exacerbates worldview defense following subtle threat (Arndt \& Greenberg, 1999). A parallel reversal holds for the influence of religiosity, which decreases mortality-salience and uncertainty-salience effects on evaluation in most contexts, but not when the target relates directly to religion (McGregor et al., 2008; van den Bos et al., 2006). Self-esteem and religiosity, therefore, do more than attenuate threat-values - they also seem to index the perceived significance of related targets (i.e., topics related to the basis of self-esteem or to religion). Conceivably, self-esteem, religiosity, and other threatmitigators reduce, but do not entirely eliminate, alarm activation in response to subtle threats, leaving individuals less reactive to most targets yet more reactive to cherished targets related to that trait. Future inquiry should probe how threat-mitigating traits can also marshal bias (for further discussion, see McGregor et al., 2009).6

Idiosyncratic personal preferences for or against a given target may also be accentuated by unconscious vigilance. Mortality-salience, for instance, leads highly neurotic, sensationaverse participants to further minimize their exposure to tactile stimulation (Goldenberg et al., 2006). Analogously, high group-identifiers - such as patriots, authoritarians, or collectivists - register complementary or critical attitudes toward that group more acutely (Landau et al., 2007; Navarrete, 2005). Such a preference-heightening dynamic may also explain why risk-seeking individuals endorse greater willingness to engage in risky behavior following mortality-salience, whereas risk-averse individuals endorse less (Rosenbloom, 2003). If a target is affectively denoted as relevant to you in a particular direction, then you may be more prone to bias consonant with these preferences when unconsciously vigilant.

\section{Unconscious Vigilance and Carryover Affect}

The unconscious vigilance model of evaluation bias overlaps with traditional models of carryover affect in key respects: Affective primes are depicted as biasing evaluations of incidental targets, and conscious awareness of affective manipulation is thought to dispel bias. However, standard models of affective carryover map trait or state-induced affect to unrelated judgments consistent with their valence (e.g., rainy weather lowers ratings of overall life satisfaction; Schwarz \& Clore, 2007). Unconscious vigilance, by contrast, depicts intensified reactivity to affective targets as biasing judgment, not a consonant "carrying over" of the valence of the manipulation. In this way, a negatively valenced alarm manipulation (e.g., a subliminal pain prime) can evoke a stronger preference for a positively valenced target.

Our studies, like the worldview defense experiments they were patterned on, employed simple measures of preferences for and against valenced targets. Intriguingly, the appraisaltendency literature reports that emotion primes which produce similar preference biases can produce distinct, or even opposing, cognitive biases based on the informational structure intrinsic to the emotion (Smith \& Ellsworth, 1985). For example, fear and anger have been observed to prompt similar decreases in liking, but opposing appraisals of risk (Lerner \& Keltner, 2000). Looking ahead, the possibility that unconsciously registered emotional cues may influence informational appraisals remains a fascinating open question. Applying

\footnotetext{
${ }^{6}$ Further complicating predictions, distinct forms of self-esteem predict distinct action tendencies (Kirkpatrick, Waugh, Valencia, \& Webster, 2002). For example, self-esteem that is based on perceived mate value predicts hostility, whereas the reverse has been found when self-esteem is rooted in social inclusion. Thus, unconscious vigilance may promote intensified hostility among those whose high self-esteem is based on mate value, but not among those whose self-esteem is based on social inclusion (also see Leary, 2000).
} 
appraisal-tendency findings to worldview defense research, subtle manipulations involving topics such as uncertainty, robbery, mortality, and social isolation may exert largely equivalent influences on many sorts of liking judgments, but quite distinct biases on judgments related to the appraisal-structure of the emotions elicited by the primes. We therefore caution the reader not to mistake our argument - that worldview defense is better explained by a relatively indiscriminate sensitization of preferences- as a claim against the prospect of unique relationships between specific classes of subtle alarm inputs and other informationally related evaluations.

\section{Worldview Defense Without Unconscious Vigilance}

Individuals discount intensified affective reactions when cognizant that these feelings may be misleading. There are three important caveats regarding this regulatory capacity, each indicating that unconscious vigilance is sufficient but not necessary to produce worldview defense. First, although individuals tend to discount the informational relevance of their negative feelings when the origins of those feelings are suspect, positive affect resists discounting (Schwarz \& Clore, 1983). Consequently, manipulations that induce consciously detectable positive feelings could conceivably prompt increased liking of the groupaffirming target, a form of worldview defense. Second, executive resources are required to discount irrelevant affect; cognitive load should therefore potentiate worldview defense despite an absence of distraction and delay following the alarm induction.7 Third, there are limits to the capacity of executive regulation to discount intense feelings; overwrought individuals may exhibit worldview defense despite awareness of incidental emotional prejudice.

\section{Conclusion}

Why do participants affirm their worldviews more ardently following subtle threats? The answer appears to be that subtle threats heighten our sensitivity to emotionally evocative stimuli. In contexts involving the evaluation of cultural attitudes, this dynamic articulates as "worldview defense"; analogous biases may be expected in alternate contexts. In this manner, the unconscious vigilance architecture may interact with situational factors to produce various functional and nonfunctional effects.

Although unconscious vigilance may be interpreted by some as a rather deflationary explanation of the psychological process underlying worldview defense, understanding factors that exacerbate or temper group prejudice remains vital. Terror management, coalitional psychology, and uncertainty management researchers have amassed a valuable corpus of data about the influence of subtle threats on a wide range of important social perceptions, judgments, and behaviors. Moreover, the claim that alarm cues spur worldview defense because of unconscious vigilance does not imply that there are no unique psychological consequences of mortality-, coalition-, or uncertainty-salience. The ways in which we confront death, nurture social relations, or resolve uncertainty all merit further inquiry.

\footnotetext{
${ }^{7}$ In fact, terror management researchers have documented this dynamic: Cognitive load may be substituted for distraction and delay to evoke worldview defense immediately following mortality-salience induction (Arndt, Greenberg, Solomon, Pyszczynski, \& Simon, 1997). For similar reasons, persons who perform poorly on tasks that require executive inhibition, such as the Stroop task, may display worldview defense despite awareness of incidental affective influence.
} 


\section{Acknowledgments}

We thank Yoshi Kashima for feedback that has greatly clarified our presentation. We also thank Jared Piazza, Dan Fessler, Graham MacDonald, Carlos Navarrete, Eleanor Rosch, Pierre Lienard, Tom Lawson, Richard Ivry, and Bruce Hood for helpful discussions.

\section{References}

Adolphs R. Fear, faces, and the human amygdala. Current Opinion in Neurobiology. 2008; 18:166172. [PubMed: 18655833]

Adolphs R, Russell JA, Tranel D. A role for the human amygdala in recognizing emotional arousal from unpleasant stimuli. Psychological Science. 1999; 10:167-171.

Andrews PA, Gangestad SW, Matthews D. Adaptationism-How to carry out an exaptationist program. Behavioral and Brain Sciences. 2002; 25:489-504. [PubMed: 12879701]

Arndt J, Allen JJ, Greenberg J. Traces of terror: Subliminal death primes and facial electromyographic indices of affect. Motivation and Emotion. 2001; 25:253-277.

Arndt J, Greenberg J. The effects of a self-esteem boost and mortality salience on responses to boost relevant and irrelevant worldview threats. Personality and Social Psychological Bulletin. 1999; 25:1331-1341.

Arndt J, Greenberg J, Pyszczynski T, Solomon S. Subliminal exposure to death-related stimuli increases defense of the cultural worldview. Psychological Science. 1997; 8:379-385.

Arndt J, Greenberg J, Solomon S, Pyszczynski T, Simon L. Suppression, accessibility of death-related thoughts, and cultural worldview defense: Exploring the psychodynamics of terror management. Journal of Personality and Social Psychology. 1997; 73:5-18. [PubMed: 9216076]

Barrett LF. Solving the emotion paradox: Categorization and the experience of emotion. Personality and Social Psychology Review. 2006; 10:20-46. [PubMed: 16430327]

Berridge, KC. Pleasure, pain, desire, and dread: Hidden core processes of emotion. In: Kahneman, D.; Diener, E.; Schwarz, N., editors. Well-being: The foundations of hedonic psychology. New York, NY: Russell Sage Foundation; 1999. p. 525-557.

Bodenhausen GV, Kramer GP, Süsser K. Happiness and stereotypic thinking in social judgment. Journal of Personality and Social Psychology. 1994; 66:621-632.

Buss DM, Haselton MG, Shackelford TK, Bleske AL, Wakefield JC. Adaptations, exaptations, and spandrels. American Psychologist. 1998; 53:533-548. [PubMed: 9612136]

Byrne, D. The attraction paradigm. San Diego, CA: Academic Press; 1971.

Cassutt M. The skull makes fashion headway. The Gazette (Colorado Springs, Colorado). 2008 Jan 11. Retrieved from http://www.juneauempire.com/stories/012408/rel_239438441.shtml.

Castano, E.; Yzerbyt, V.; Paladino, M. Transcending oneself through social identification. In: Greenberg, J.; Koole, SL.; Pyszczynski, T., editors. Handbook of experimental existential psychology. New York, NY: Guilford Press; 2004. p. 305-321.

Cox CR, Goldenberg JL, Arndt J, Pyszczynski T. Mother's milk: An existential perspective on negative reactions to breastfeeding. Personality and Social Psychology Bulletin. 2007; 33:110 122. [PubMed: 17178934]

Darwin, C. On the origin of species by means of natural selection, or the preservation of favoured races in the struggle for life. 2nd ed.. London, England: John Murray; 1860.

Davis M, Whalen PJ. The amygdala: Vigilance and emotion. Molecular Psychiatry. 2001; 6:13-34. [PubMed: 11244481]

Dechesne M, Janssen J, van Knippenberg A. Defense and distancing as terror management strategies: The moderating role of need for structure and permeability of group boundaries. Journal of Personality and Social Psychology. 2000; 79:923-932. [PubMed: 11138761]

Dechesne M, Pyszczynski T, Arndt J, Ransom S, Sheldon K, Van Knippenberg A, Janssen J. Literal and symbolic immortality: The effect of evidence of literal immortality on self-esteem striving in response to mortality salience. Journal of Personality and Social Psychology. 2003; 84:722-737. [PubMed: 12703645] 
Eisenberger NI, Lieberman MD. Why rejection hurts: A common neural alarm system for physical and social pain. Trends in Cognitive Sciences. 2004; 8:294-300. [PubMed: 15242688]

Finley R. SurveyMonkey [Computer software]. 2008 Retrieved from SurveyMonkey.com.

Gailliot MT, Sillman TF, Schmeichel BJ, Maner JK, Plant EA. Mortality salience increases adherence to salient norms and values. Personality and Social Psychology Bulletin. 2008; 34:993-1003. [PubMed: 18550864]

Goldenberg JL, Hart J, Pyszczynski T, Warnica GM, Landau M, Thomas L. Terror of the body: Death, neuroticism, and the flight from physical sensation. Personality and Social Psychology Bulletin. 2006; 32:1264-1277. [PubMed: 16902244]

Goldenberg JL, Pyszczynski T, Greenberg J, Solomon S, Kluck B, Cornwell R. I am not an animal: Mortality salience, disgust, and the denial of human creatureliness. Journal of Experimental Psychology: General. 2001; 130:427-435. [PubMed: 11561918]

Gould SJ, Vrba ES. Exaptation-A missing term in the science of form. Paleobiology. 1982; 8:4-15.

Greenberg J. Understanding the vital human quest for self-esteem. Perspectives on Psychological Science. 2008; 3:48-55.

Greenberg J, Arndt J, Schimel J, Pyszczynski T, Solomon S. Clarifying the function of mortalitysalience induced worldview defense: Renewed suppression or reduced accessibility of deathrelated thoughts? Journal of Experimental Social Psychology. 2001; 37:70-76.

Greenberg J, Pyszczynski T, Solomon S, Pinel E, Simon L, Jordan K. Effects of self-esteem on vulnerability-denying defensive distortions: Further evidence of an anxiety-buffering function of self-esteem. Journal of Experimental Social Psychology. 1993; 29:229-251.

Greenberg J, Pyszczynski T, Solomon S, Rosenblatt A, Veeder M, Kirkland S, Lyon D. Evidence for terror management II: The effects of mortality salience on reactions to those who threaten or bolster the cultural worldview. Journal of Personality and Social Psychology. 1990; 58:308-318.

Greenberg J, Pyszczynski T, Solomon S, Simon L, Breus M. Role of consciousness and accessibility of death-related thoughts in mortality salience effects. Journal of Personality and Social Psychology. 1994; 67:627-637. [PubMed: 7965609]

Greenberg J, Simon L, Harmon-Jones E, Solomon S, Pyszczynski T, Chatel D. Testing alternative explanations for mortality effects: Terror management, value accessibility, or worrisome thoughts? European Journal of Social Psychology. 1995; 25:417-433.

Greenberg, J.; Solomon, S.; Pyszczynski, T. Terror management theory of self-esteem and social behavior: Empirical assessments and conceptual refinements. In: Zanna, MP., editor. Advances in experimental social psychology. Vol. Vol. 29. New York, NY: Academic Press; 1997. p. 61-139.

Gudykunst, WB. Toward a theory of effective interpersonal and intergroup communication: An anxiety/uncertainty management (AUM) perspective. In: Wiseman, R.; Koester, J., editors. Intercultural communication competence. Newbury Park, CA: Sage; 1993. p. 33-71.

Hariri AR, Bookheimer SY, Mazziotta JC. A neural network for modulating the emotional response to faces. NeuroReport. 2000; 11:43-48. [PubMed: 10683827]

Hariri AR, Tessitore A, Mattay VS, Fera F, Weinberger DR. The amygdala response to emotional stimuli: A comparison of faces and scenes. NeuroImage. 2002; 17:317-323. [PubMed: 12482086]

Harmon-Jones E, Simon L, Greenberg J, Pyszczynski T, Solomon S, McGregor H. Terror management theory and self-esteem: Evidence that increased self-esteem reduces mortality salience effects. Journal of Personality and Social Psychology. 1997; 72:24-36. [PubMed: 9008372]

Herry C, Bach DR, Esposito F, Di Salle F, Perrig WJ, Scheffler K, Seifritz E. Processing of temporal unpredictability in human and animal amygdala. The Journal of Neuroscience. 2007; 27:59585966. [PubMed: 17537966]

Holbrook C. The terror of the gods: Evidence from Tibet against terror management theory. 2011 Manuscript submitted for publication.

Holland PC, Gallagher M. Amygdala circuitry in attentional and representational processes. Trends in Cognitive Sciences. 1999; 3:65-73. [PubMed: 10234229]

Inzlicht M, McGregor I, Hirsh JB, Nash KA. Neural markers of religious conviction. Psychological Science. 2009; 20:385-392. [PubMed: 19291205] 
Jiang Y, Costello P, Fang F, Huang M, He S. Gender and sexual orientation dependent attentional effect of invisible images. Proceedings of the National Academy of Sciences, USA. 2006; 103:17048-17052.

Jonas E, Fischer P. Terror management and religion-Evidence that intrinsic religiousness mitigates worldview defense following mortality salience. Journal of Personality and Social Psychology. 2006; 91:553-567. [PubMed: 16938037]

Kasser T, Sheldon KM. Of wealth and death: Materialism, mortality salience, and consumption behavior. Psychological Science. 2000; 11:348-351. [PubMed: 11273398]

Kehner D, Locke KD, Aurain PC. The influence of attributions on the relevance of negative emotions to personal satisfaction. Personality and Social Psychology Bulletin. 1993; 19:21-29.

Kirk, RE. Experimental design: Procedures for the behavioural sciences. 3rd ed.. Pacific Grove, CA: Brooks/Cole; 1995.

Kirkpatrick L, Navarrete CD. "Reports of my death have been greatly exaggerated": A critique of terror management theory from an evolutionary perspective. Psychological Inquiry. 2006; 17:288298.

Kirkpatrick LA, Waugh CE, Valencia A, Webster GD. The functional domain-specificity of selfesteem and the differential prediction of aggression. Journal of Personality and Social Psychology. 2002; 82:756-767. [PubMed: 12003475]

Landau MJ, Greenberg J, Solomon S, Pyszczynski T, Martens A. Windows into nothingness: Terror management, meaninglessness, and negative reactions to modern art. Journal of Personality and Social Psychology. 2006; 90:879-892. [PubMed: 16784340]

Landau MJ, Johns M, Greenberg J, Pyszczynski T, Solomon S, Martens A. A function of form: Terror management and structuring of the social world. Journal of Personality and Social Psychology. 2004; 87:190-210. [PubMed: 15301627]

Landau MJ, Solomon S, Pyszczynski T, Greenberg J. On the compatibility of terror management theory and perspectives on human evolution. Evolutionary Psychology. 2007; 5:476-519.

Leary, MR. Affect, cognition, and the social emotions. In: Forgas, JP., editor. Feeling and thinking: The role of affect in social cognition. New York, NY: Cambridge University Press; 2000. p. 331-356.

LeDoux, JE. The emotional brain. New York, NY: Simon \& Schuster; 1996.

Lerner JS, Keltner D. Beyond valence: Toward a model of emotion-specific influences on judgment and choice. Cognition \& Emotion. 2000; 14:473-493.

Liddell BJ, Brown KJ, Kemp AH, Barton MJ, Das P, Peduto A, Williams LM. A direct brainstemamygdala-cortical "alarm" system for subliminal signals of fear. NeuroImage. 2005; 24:235-243. [PubMed: 15588615]

Lieberman MD. Social cognitive neuroscience: A review of core processes. Annual Review of Psychology. 2007; 58:259-289.

Lieberman MD, Eisenberger NI, Crockett MJ, Tom SM, Pfeifer JH, Way BM. Putting feelings into words: Affect labeling disrupts amygdala activity to affective stimuli. Psychological Science. 2007; 18:421-428. [PubMed: 17576282]

Lieberman MD, Jarcho JM, Berman S, Naliboff B, Suyenobu BY, Mandelkern M, Mayer E. The neural correlates of placebo effects: A disruption account. NeuroImage. 2004; 22:447-455. [PubMed: 15110038]

Loewenstein, G.; Lerner, JS. The role of affect in decision making. In: Davidson, R.; Goldsmith, H.; Scherer, K., editors. Handbook of affective science. Oxford, England: Oxford University Press; 2003. p. 619-642.

Martin LL, Harlow TF, Strack F. The role of bodily sensations in the evaluation of social events. Personality and Social Psychology Bulletin. 1992; 18:412-419.

Matsumoto, D.; Ekman, P. Japanese and Caucasian Facial Expressions of Emotion (JACFEE) and Neutral Faces (JACNeuF) [Slides]. San Francisco, CA: Human Interaction Laboratory, University of California, San Francisco; 1988.

McGregor I. Offensive defensiveness: Toward an integrative neuroscience of compensatory zeal after mortality salience, personal uncertainty, and other poignant self-threats. Psychological Inquiry. 2006; 17:299-308. 
McGregor I, Haji R, Nash KA, Teper R. Religious zeal and the uncertain self. Basic and Applied Social Psychology. 2008; 30:183-188.

McGregor I, Marigold DC. Defensive zeal and the uncertain self: What makes you so sure? Journal of Personality and Social Psychology. 2003; 85:838-852. [PubMed: 14599248]

McGregor I, Nash K, Inzlicht M. Threat, high self-esteem, and reactive approach motivation: Electroencephalographic evidence. Journal of Experimental Social Psychology. 2009; 45:10031007.

McGregor I, Zanna MP, Holmes JG, Spencer SJ. Compensatory conviction in the face of personal uncertainty: Going to extremes and being oneself. Journal of Personality and Social Psychology. 2001; 80:472-488. [PubMed: 11300580]

Millisecond Software. Inquisit 3.0.1.0 [Computer software]. Seattle, WA: Author; 2008.

Navarrete CD. Mortality concerns and other adaptive challenges: The effects of coalition-relevant challenges on worldview defense in the U.S. and Costa Rica. Group Processes \& Intergroup Relations. 2005; 8:411-427.

Navarrete CD, Fessler DM. Normative bias and adaptive challenges: A relational approach to coalitional psychology and a critique of terror management theory. Evolutionary Psychology. 2005; 3:297-325.

Navarrete CD, Fessler DM. Disease avoidance and ethnocentrism: The effects of disease vulnerability and disgust sensitivity on intergroup attitudes. Evolution and Human Behavior. 2006; 27:270-282.

Navarrete CD, Kurzban R, Fessler DM, Kirkpatrick L. Anxiety and intergroup bias: Terrormanagement or coalitional psychology? Group Processes \& Intergroup Relations. 2004; 7:370397.

Nitschke JB, Sarinopoulos I, Oathes DJ, Johnstone T, Whalen PJ, Davidson RJ, Kalin NH. Anticipatory activation in the amygdala and anterior cingulate in generalized anxiety disorder and prediction of treatment response. The American Journal of Psychiatry. 2009; 166:302-310. [PubMed: 19122007]

Pham MT. Emotion and rationality: A critical review and interpretation of empirical evidence. Review of General Psychology. 2007; 11:155-178.

Prinz, J. Gut reactions: A perceptual theory of emotion. New York, NY: Oxford University Press; 2004.

Pyszczynski T, Greenberg J, Solomon S. A dual-process model of defense against conscious and unconscious death-related thoughts: An extension of terror management theory. Psychological Review. 1999; 106:835-845. [PubMed: 10560330]

Rosenblatt A, Greenberg J, Solomon S, Pyszczynski T, Lyon D. Evidence for terror management theory I: The effects of mortality salience on reactions to those who violate or uphold cultural values. Journal of Personality and Social Psychology. 1989; 57:681-690. [PubMed: 2795438]

Rosenbloom T. Sensation seeking and risk taking in mortality salience. Personality and Individual Differences. 2003; 35:1809-1819.

Routledge C, Arndt J, Goldenberg JL. A time to tan: Proximal and distal effects of mortality salience on sun exposure intentions. Personality and Social Psychology Bulletin. 2004; 30:1347-1358. [PubMed: 15466606]

Schimel J, Simon L, Greenberg J, Pyszczynski T, Solomon S, Waxmonski J, Arndt J. Support for a functional perspective on stereotypes: Evidence that mortality salience enhances stereotypic thinking and preferences. Journal of Personality and Social Psychology. 1999; 77:905-926. [PubMed: 10573872]

Schwarz N, Clore GL. Mood, misattribution, and judgments of well-being: Informative and directive functions of affective states. Journal of Personality and Social Psychology. 1983; 45:513-523.

Schwarz, N.; Clore, GL. Feelings and phenomenal experiences. In: Higgins, ET.; Kruglanski, A., editors. Social psychology: Handbook of basic principles. 2nd ed.. New York, NY: Guilford Press; 2007. p. 385-407.

Smith CA, Ellsworth PC. Patterns of cognitive appraisal in emotion. Journal of Personality and Social Psychology. 1985; 48:813-838. [PubMed: 3886875]

Thornhill, R. The concept of an evolved adaptation. In: Bock, G.; Cardew, G., editors. Characterizing human psychological adaptations. London, England: CIBA Foundation; 1997. p. 4-22. 
Tooby, J.; Cosmides, L. Conceptual foundations of evolutionary psychology . In: Buss, DM., editor. The handbook of evolutionary psychology. Hoboken, NJ: Wiley; 2005. p. 5-67.

van den Bos K. Uncertainty management: The influence of uncertainty salience on reactions to perceived procedural fairness. Journal of Personality and Social Psychology. 2001; 80:931-941. [PubMed: 11414375]

van den Bos K, Ham J, Lind EA, Simonis M, van Essen WJ, Rijpkema M. Justice and the human alarm system: The impact of exclamation points and flashing lights on the justice judgment process. Journal of Experimental Social Psychology. 2008; 44:201-219.

van den Bos K, Poortvliet PM, Maas M, Miedema J, van den Ham EJ. An enquiry concerning the principles of cultural norms and values: The impact of uncertainty and mortality salience on reactions to violations and bolstering of cultural worldviews. Journal of Experimental Social Psychology. 2005; 41:91-113.

van den Bos K, van Ameijde J, van Gorp H. On the psychology of religion: The role of personal uncertainty in religious worldview defense. Basic and Applied Social Psychology. 2006; 28:333341.

Wager, TD.; Barrett, LF.; Bliss-Moreau, E.; Lindquist, K.; Duncan, S.; Kober, H.; Mize, J. The neuroimaging of emotion. In: Lewis, M.; Haviland-Jones, JM.; Barrett, LF., editors. Handbook of emotions. New York, NY: Guilford Press; 2008. p. 249-271.

Watson, D.; Clark, LA. Preliminary manual for the PANAS-X: Positive and Negative Affect Schedule —Expanded Form. University Park, TX: Southern Methodist University; 1991. Unpublished manuscript

Whalen PJ, Kagan J, Cook RG, Davis FC, Kim H, Polis S, Johnstone T. Human amygdala responsivity to masked fearful eye whites. Science. 2004 Dec 17.306:2061. [PubMed: 15604401]

Whalen PJ, Rauch SL, Etcoff NL, McInerney SC, Lee M, Jenike MA. Masked presentations of emotional facial expressions modulate amygdala activity without explicit knowledge. The Journal of Neuroscience. 1998; 18:411-418. [PubMed: 9412517]

Williams, GC. Adaptation and natural selection. Princeton, NJ: Princeton University Press; 1966.

Williams LM, Liddell BJ, Kemp AH, Bryant RA, Meares RA, Peduto AS, Gordon E. Amygdalaprefrontal dissociation of subliminal and supraliminal fear. Human Brain Mapping. 2006; 27:652661. [PubMed: 16281289]

Winkielman P, Berridge KC. Unconscious emotion. Current Directions in Psychological Science. 2004; 13:120-123.

Winkielman, P.; Berridge, KC.; Wilbarger, JL. Emotion, behavior, and conscious experience: Once more without feeling. In: Barrett, LF.; Niedenthal, P.; Winkielman, P., editors. Emotion and consciousness. New York, NY: Guilford Press; 2005a. p. 335-362.

Winkielman P, Berridge KC, Wilbarger JL. Unconscious affective reactions to masked happy versus angry faces influence consumption behavior and judgments of value. Personality and Social Psychology Bulletin. 2005b; 31:121-135. [PubMed: 15574667]

Winkielman P, Knutson B, Paulus MP, Trujillo JT. Affective influence on decisions: Moving towards the core mechanisms. Review of General Psychology. 2007; 11:179-192.

Wisman A, Goldenberg JL. From the grave to the cradle: Evidence that mortality salience engenders a desire for offspring. Journal of Personality and Social Psychology. 2005; 89:46-61. [PubMed: 16060742]

Wright CI, Fischer H, Whalen PJ, McInerney SC, Shin LM, Rauch SL. Differential prefrontal cortex and amygdala habituation to repeatedly presented emotional stimuli. NeuroReport. 2001; 12:379383. [PubMed: 11209954] 


\section{Gender Classification Task (8 Trials)}

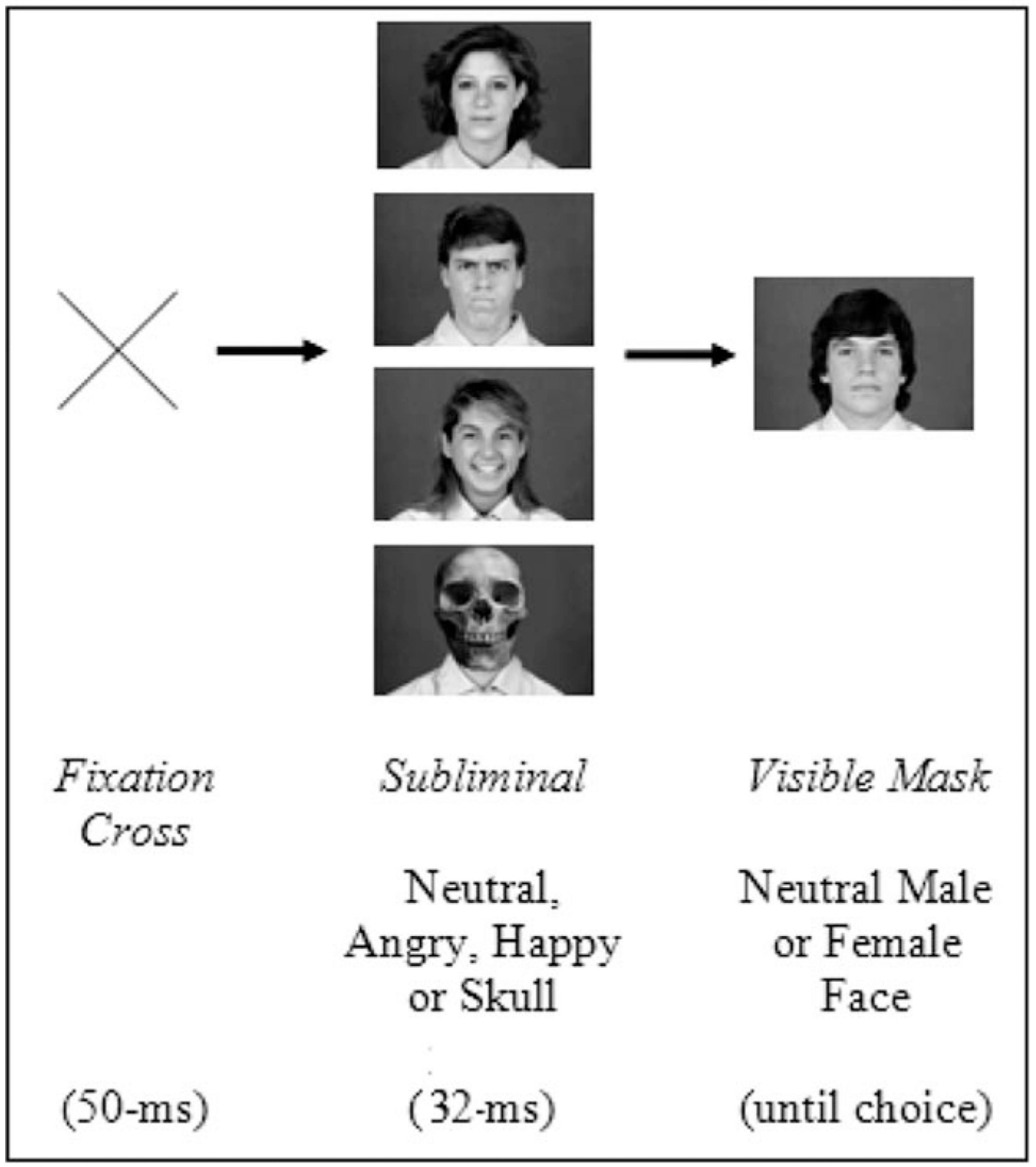

Figure 1.

In Study 3, participants were primed with a series of subliminal emotion faces (or skulls) embedded within a gender classification task (modified from Winkielman et al., 2005b). Immediately following this task, participants rated the authors of a pair of pro- and anti-U.S. essays. Note: The face images used in this figure are from the Japanese and Caucasian Facial Expressions of Emotion (JACFEE) and Neutral Faces (JACNeuF) set (Matsumoto \& Ekman, 1988). 


\section{Table 1}

Influence of Mortality-Salience on Evaluations of Worldview-Neutral Stimuli

\begin{tabular}{llll}
\hline Bias type & Control & Death & $\boldsymbol{F}$ \\
\hline Sound bias (Study 1) & & & \\
$M$ & 4.98 & 6.24 & $4.84^{*}$ \\
& & \\
& & & \\
Image bias (Study 2) & & & \\
$M$ & 4.99 & 6.45 & $5.02^{*}$ \\
$S D$ & 2.69 & 1.81 & \\
\hline
\end{tabular}

* $p<.05$. 
Table 2

Influence of Exposure to Subliminal Faces on Pro-U.S. Bias

\begin{tabular}{cllll}
\hline & \multicolumn{4}{c}{ Experimental condition } \\
\cline { 2 - 5 } Pro-U.S. bias & Neutral & Angry & Happy & Skull \\
\hline$M$ & $1.7^{\mathrm{a}}$ & $2.65^{\mathrm{b}}$ & $2.13^{\mathrm{a}, \mathrm{b}}$ & $2.04^{\mathrm{a}, \mathrm{b}}$ \\
$S D$ & 1.29 & 1.81 & 1.27 & 1.41 \\
\hline
\end{tabular}

Note. Means with different superscripts are significantly different with alpha at 05 . 
Table 3

Influence of Exposure to Subliminal Words on Pro-U.S. Bias

\begin{tabular}{clll}
\hline & \multicolumn{3}{c}{ Experimental condition } \\
\cline { 2 - 4 } Pro-U.S. bias & Field & Pain & Dead \\
\hline$M$ & $1.53^{\mathrm{a}}$ & $2.11^{\mathrm{b}}$ & $2.5^{\mathrm{b}}$ \\
$S D$ & 1.38 & 1.92 & 1.63 \\
\hline
\end{tabular}

Note. Means with different superscripts are significantly different with alpha at 05 . 
Table 4

Types of Evaluations Influenced by Mortality-Salience

\begin{tabular}{ll}
\hline Mortality-salience increases & Studies \\
\hline Worldview defense & Greenberg et al., 1990 \\
Religious conviction & Jonas \& Fischer, 2006 \\
Stereotyping & Schimel et al., 1999 \\
Dislike of nonrepresentational art & Landau et al., 2006 \\
Dislike of public breastfeeding & Cox et al., 2007 \\
National identification & Castano et al., 2004 \\
Conformity to social norms & Gailliot et al., 2008 \\
Dislike of inconsistent behavior & Landau et al., 2004 \\
Dislike of sensation (for neurotics) & Goldenberg et al., 2006 \\
Desire for luxury goods & Kasser \& Sheldon, 2000 \\
Desire to have children & Wisman \& Goldenberg, 2005 \\
Belief in a just world & Landau et al., 2004 \\
Sun tanning to appear attractive & Routledge et al., 2004 \\
Seeing humans as unlike animals & Goldenberg et al., 2001 \\
\hline
\end{tabular}

Note. This list is intended to be representative but not exhaustive. 